\title{
Metformin in combination with 5-fluorouracil suppresses tumor growth by inhibiting the Warburg effect in human oral squamous cell carcinoma
}

\author{
KOJI HARADA, TARANNUM FERDOUS, TOYOKO HARADA and YOSHIYA UEYAMA
}

Department of Oral and Maxillofacial Surgery, Yamaguchi University Graduate School of Medicine, Ube 755-8505, Japan

Received January 23, 2016; Accepted March 7, 2016

DOI: $10.3892 /$ ijo.2016.3523

\begin{abstract}
Cancer cells show enhanced glucose consumption and lactate production even in the presence of abundant oxygen, a phenomenon known as the Warburg effect, which is related to tumor proliferation, progression and drug-resistance in cancers. Hypoxia-inducible factor-1 (HIF-1) and several members of Phosphatidylinositol-4, 5-bisphosphate 3-kinase (PI3K)/AKT/mammalian target of rapamycin (mTOR) signaling pathway positively contribute to the Warburg effect, whereas AMP activated protein Kinase (AMPK) acts as a negative regulator. Targeting the regulator molecules of Warburg effect might be a useful strategy to effectively kill cancer cells. Metformin was reported to be effective against various cancers as it inhibits cell proliferation by activating AMPK, and inhibiting mTOR and HIF-1 $\alpha$. Several studies suggested the efficacy of metformin with 5-fluorouracil (5-FU) against esophageal and colon cancer. In this study, we evaluated the efficacy of metformin and 5-FU combined therapy against human oral squamous cell carcinoma (OSCC) in vitro and in vivo. MTT assay and TUNEL assay revealed that metformin $(4 \mathrm{mg} / \mathrm{ml})$ and $5-\mathrm{FU}(2.5 \mu \mathrm{g} / \mathrm{ml})$ combination treatment effectively inhibited cell growth and induced apoptosis in OSCC cell lines (HSC2, HSC3 and HSC4) compared to either agent alone. Lactate colorimetric assay detected decreased level of lactate in the supernatants of metformin and 5-FU treated cells compared to cells treated with metformin or 5-FU. Western blot analysis showed marked downregulation of HIF-1 $\alpha$ and mTOR expression, and upregulation of AMPK $\alpha$ in cells treated with metformin and 5-FU combination treatment. Combination therapy with metformin $(200 \mathrm{mg} / \mathrm{kg}$, i.p.) and 5-FU (10 mg/kg, i.p.) for 4 weeks (5 days/week) effectively reduced HSC2 tumor growth $(77.6 \%)$ compared to metformin $(59.9 \%)$ or $5-\mathrm{FU}(52 \%)$ alone in nude mice. These findings
\end{abstract}

Correspondence to: Dr Koji Harada, Department of Oral and Maxillofacial Surgery, Yamaguchi University Graduate School of Medicine, 1-1-1 Minamikogushi, Ube 755-8505, Japan

E-mail: harako@yamaguchi-u.ac.jp

Key words: 5-Fluorouracil, metformin, Warburg effect, oral squamous cell carcinoma suggest that metformin and 5-FU combined therapy could exert strong antitumor effect against OSCC through the inhibition of Warburg phenomenon in tumor cells.

\section{Introduction}

Oral squamous cell carcinoma (OSCC) is the most common cancer of the oral cavity; it accounts for more than $90 \%$ all oral neoplasms (1). Oral cancers account for $2-4 \%$ of all cancer cases worldwide and OSCC is the 8th most common cancer in humans $(2,3,4)$. For several decades increasing trends of oral cancer incidences have been observed in either gender in the general population all over the world $(5,6)$. Current approaches of treatment of OSCC include surgery, radiation therapy and/or chemotherapy. However, despite the progress in research and therapy, survival has not improved considerably in recent years (7). If detected during its early stage, the 5-year survival rate of oral cancer is $60-80 \%(1,8)$. However, the overall survival rate of OSCC is approximately $50 \%$ in the advanced stage of the disease $(9,10)$. Moreover, these therapeutic approaches usually cause adverse effects that reduce quality of life. Therefore, it is necessary to identify novel, effective and less cytotoxic therapeutic agents for OSCC treatment.

Proliferating tumor cells do not exploit the full capacity of oxidative metabolism of glucose to produce ATP, instead it shows enhanced lactate production during glucose metabolism even in the presence of abundant oxygen (11). This phenomenon is known as the Warburg effect or aerobic glycolysis, which is a common metabolic characteristic of cancer cells and is related to tumor proliferation, progression and drugresistance in cancer $(12,13)$. The Warburg effect has been directly associated with the upregulation of HIF-1 $\alpha$ and lactate dehydrogenase (LDH) as well as downregulation of pyruvate dehydrogenase (PDH) (14,15). Several members of PI3K/ AKT/mTOR signaling pathway are recognized as the major control points to support the metabolic autonomy of tumor cells and the Warburg effect (14-16). Herein, Akt acts as a key enzyme of the Warburg effect in tumor cells by favoring the glucose-to-lactate metabolic pathway. PI3K and mTOR are located up- and down-stream of Akt respectively, and also act as active players (16). On the contrary, it was reported that, silencing AMPK in tumor cells results in a metabolic shift towards aerobic glycolysis. HIF-1 $\alpha$ has a significant role in this 
metabolic shift, therefore AMPK acts as a negative regulator of the Warburg effect (17). Targeting the regulator molecules of Warburg effect might be a useful strategy to overcome drug-resistance and effectively kill cancer cells.

Metformin, a low cost antidiabetic drug has been reported to be effective in the treatment of different types of cancers including oral cancer and head and neck cancer, and it is well tolerated by patients (18-27). Metformin exerts inhibitory effects on multiple pathways involved in the initiation of carcinogenesis, as well as proliferation, survival and metastasis of cancer cells (28). It targets cancer stem cells and several regulatory molecules of Warburg effect, and it also induces apoptosis in cancer cells (29). Merformin inhibits cell proliferation by activating AMPK, and inhibiting mTOR and HIF-1 $\alpha$ (30). It can also ameliorate the cytotoxicity of some drugs and several studies demonstrated the combined effect of metformin and 5-fluorouracil (5-FU) against esophageal and colon cancer cells $(31,32)$.

In this study, we evaluated the efficacy of combined therapy with metformin and 5-FU against human OSCC cell lines in vitro and in vivo.

\section{Materials and methods}

Cell lines and cell culture. OSCC cell lines (HSC2, HSC3 and HSC4) were obtained from Cell Bank, RIKEN BioResource Center (Ibaraki, Japan). Cells were cultured in Dulbecco's modified Eagle's medium (DMEM) (Sigma-Aldrich, St. Louis, MO, USA) supplemented with $10 \%$ fetal bovine serum (FBS) (Thermo Fisher Scientific Inc., Waltham, MA, USA), $100 \mu \mathrm{g} / \mathrm{ml}$ streptomycin, $100 \mathrm{U} / \mathrm{ml}$ penicillin (Thermo Fisher Scientific) in a humidified atmosphere containing $5 \% \mathrm{CO}_{2}$.

In vitro cell growth assay. Cells $\left(5 \times 10^{3}\right.$ per well) were seeded on 96-well plates (Becton Dickinson Labware, Franklin lakes, NJ, USA) in DMEM supplemented with 10\% FBS. Twenty-four hours later, the cells were treated with 5-FU (0.5-10 $\mu \mathrm{g} / \mathrm{ml})$ (Kyowa Hakko Kirin Co., Ltd, Tokyo, Japan), Metformin hydrochloride (metformin; 1-10 mg/ml) (Wako Pure Chemical Industries, Ltd., Osaka, Japan) or both for 24,48 or $72 \mathrm{~h}$. Then, 3-(4, 5-dimethylthiazol-2-yl)-2, 5-diphenyltetrazolium bromide (MTT) was added to each well $(25 \mu \mathrm{l} /$ well $)$ and incubated for $4 \mathrm{~h}$. The blue dye taken up by cells was dissolved in dimethyl sulfoxide (100 $\mu \mathrm{l} /$ well), and the absorbance was measured with a spectrophotometer (Bio-Rad Laboratories, Hercules, CA, USA) at $490 \mathrm{~nm}$. All assays were run in triplicate.

TUNEL (terminal deoxynucleotidyl transferase (Tdt)-mediated nick end labeling) assay. To detect apoptotic cells in cell lines and in mouse tumor tissues, TUNEL assay was performed by labeling 3'-OH DNA ends generated by DNA fragmentation. Cells $\left(5 \times 10^{3}\right.$ cells per well) were seeded on cover glass (Matsunami Glass Ind. Ltd., Osaka, Japan) in DMEM containing $10 \%$ FBS. After incubation for $24 \mathrm{~h}$, cells were treated with 5-FU $(2.5 \mu \mathrm{g} / \mathrm{ml})$ and/or metformin $(4 \mathrm{mg} / \mathrm{ml})$ and incubated for $48 \mathrm{~h}$. Then, the cells on the cover glass were washed twice with phosphate buffered saline (PBS), air dried, and fixed in $4 \%$ paraformaldehyde at room temperature for $30 \mathrm{~min}$. The TUNEL assay was performed using a
DeadEnd $^{\mathrm{TM}}$ Colorimetric TUNEL System according to the manufacturer's instructions (Promega Corp., Madison, WI, USA). Briefly, the cells on the cover glass were incubated in $20 \mu \mathrm{g} / \mathrm{ml}$ proteinase $\mathrm{K}$ for $15 \mathrm{~min}$. Endogenous peroxidase of cells on the cover glass was blocked by incubating in a $3 \%$ hydrogen peroxide solution for $5 \mathrm{~min}$ after cells were rinsed in distilled water. After being washed with PBS, the cells were incubated with equilibration buffer $(0.05 \mathrm{M}$ phosphate buffer containing $0.145 \mathrm{M}$ sodium chloride, $\mathrm{pH} 7.4$ ) and then Tdt enzyme in a humidified chamber at $37^{\circ} \mathrm{C}$ for $60 \mathrm{~min}$. They were subsequently put into pre-warmed working strength stop wash buffer for $10 \mathrm{~min}$. After being rinsed in PBS, the cells were incubated with anti-digoxigenin-peroxidase conjugate for $30 \mathrm{~min}$. Peroxidase activity in each cell was demonstrated by the application of diaminobenzidine. Hematoxylin was used as a counterstain. At least 1000 cells were counted under a microscope in three random fields of each cover glass. The number of apoptotic cells was calculated by dividing the number of TUNEL positive cells by the total number of counted cells and the result was expressed as a percentage.

In the same manner, TUNEL assay was performed in $4 \mu \mathrm{m}$ paraffin sections of mouse tumor tissues using a DeadEnd Colorimetric TUNEL System according to the manufacturer's instructions (Promega Corp.).

Lactate colorimetric assay. To detect the lactate production from 5 -FU $(2.5 \mu \mathrm{g} / \mathrm{ml})$ and/or metformin $(4 \mathrm{mg} / \mathrm{ml})$ treated cells, lactate colorimetric assay was carried out to measure the total lactate content in the cell culture supernatant of the untreated control, 5-FU $(2.5 \mu \mathrm{g} / \mathrm{ml})$ and/or metformin ( $4 \mathrm{mg} / \mathrm{ml}$ ) treated cells for $48 \mathrm{~h}$ using a Lactate Assay kit according to the manufacturer's instructions (BioVision Inc., Milpitas, CA, USA).

Western blot analysis. After the cells were treated with 5-FU $(2.5 \mu \mathrm{g} / \mathrm{ml})$ and/or metformin $(4 \mathrm{mg} / \mathrm{ml})$ for $48 \mathrm{~h}$, they were collected and lysed. Whole cell lysates were subjected to electrophoresis on $10 \%$ SDS-polyacrylamide gels, and then transferred to a PVDF membrane. The membranes were incubated with the anti-HIF-1 $\alpha$ mouse monoclonal antibody (Santa Cruz Biotechnology, Inc., Santa Cruz, CA, USA), anti-mTOR rabbit monoclonal antibody (Cell Signaling Technology Inc., Danvers, MA, USA), anti-Akt1 mouse monoclonal antibody (Santa Cruz), and anti-AMPK $\alpha$ rabbit monoclonal antibody (Cell Signaling Technology Inc.) followed by Novex ${ }^{\circledR}$ alkaline-phosphatase conjugated (goat) anti-rabbit or (goat) anti-mouse immunoglobulin $\mathrm{G}$ ( $\mathrm{IgG}$ ) secondary antibody (Thermo Fisher Scientific). The antibody was detected using a chromogenic immunodetection system, WesternBreeze (Thermo Fisher Scientific) according to the manufacturer's instructions. Moreover, anti- $\alpha-$ tubulin monoclonal antibody (Santa Cruz Biotechnology, Inc.) was used for normalization of western blot analysis.

Nude mice and tumor inoculations. Female athymic nude mice with CAnN.Cg-Foxnlnu/CrlCrlj genetic background (CLEA Japan, Inc. Tokyo, Japan) were purchased at 4 weeks of age and kept under sterile conditions in a pathogen-free environment. The mice were provided with sterile water and food. In addition, all manipulations were carried out aseptically inside a laminar flow hood. Cells were used as a xenograft model in 
the nude mice. Briefly, cells $\left(1 \times 10^{6}\right)$ were suspended in $0.1 \mathrm{ml}$ of serum-free medium and injected into the subcutaneous tissue of 5-week-old nude mice (average weight $20.0 \mathrm{~g}$ ) using a 27 -gauge needle. Tumors were allowed to grow for 14 days before treatment. The mice were then divided into 4 groups, 5 mice in each group with similar mean tumor volumes $\left(600-800 \mathrm{~mm}^{3}\right)$. All in vivo experiments were approved by the Institutional Animal Care and Use Committee of Yamaguchi University.

In vivo treatment protocol. For this experiment, suitable doses for $5-\mathrm{FU}$ and metformin were selected as 10 and $200 \mathrm{mg} / \mathrm{kg}$, respectively, as these doses were reported to be effective in tumor xenograft models of other cancer types $(33,34)$. The treatment protocol of the four experimental groups of mice is shown in Fig. 5A. After tumor formation, these mice were treated with sterile saline $(100 \mu \mathrm{l}), 5-\mathrm{FU}(10 \mathrm{mg} / \mathrm{kg})$ and/or metformin $(200 \mathrm{mg} / \mathrm{kg})$ by intraperitoneal (i.p.) injection for 4 weeks (5 days/week).

The size of the tumors was measured every three days and tumor volumes were calculated as $0.5 \mathrm{x}$ length $\mathrm{x}$ width ${ }^{2}$. At 28 days, mice were sacrificed by an overdose of Somnopentyl (200 mg/kg; Merck \& Co., Inc., Whitehouse Station, NJ, USA), and the tumors were dissected, fixed in neutral-buffered formalin and embedded in paraffin for further study.

Immunohistochemistry. The avidin-biotin complex immunohistochemical technique was used to detect Warburg effect related factors (HIF-1- $\alpha$, mTOR, Akt1 and AMPK $\alpha$ ) in mouse tissue specimens, using the EnVision ${ }^{\mathrm{TM}}$ kit (Dako, Glostrup, Denmark). Paraffin-embedded $4 \mu \mathrm{m}$ tissue sections were deparaffinized in xylene and rehydrated through graded alcohols. Endogenous peroxidase was quenched with a $0.3 \%$ hydrogen peroxide/methanol mixture for $30 \mathrm{~min}$. Sections were rinsed and pre-incubated with $2 \%$ blocking serum for $30 \mathrm{~min}$, followed by incubation with the anti-HIF-1 $\alpha$ mouse monoclonal antibody (Santa Cruz Biotechnology, Inc.), anti-mTOR rabbit monoclonal antibody (Cell Signaling Technology Inc.), antiAkt1 mouse monoclonal antibody (Santa Cruz Biotechnology, Inc.), and anti-AMPK $\alpha$ rabbit monoclonal antibody (Cell Signaling Technology Inc.) for $8 \mathrm{~h}$ at $4^{\circ} \mathrm{C}$. After rinsing the tissue sections in phosphate buffered saline (PBS) for $10 \mathrm{~min}$, the antibody was detected using the EnVision kit according to the manufacturer's instructions. Tissues were finally rinsed in PBS for $5 \mathrm{~min}$ followed by tap water for $5 \mathrm{~min}$, and then counterstained with hematoxylin for $1 \mathrm{~min}$. The tissue sections were subsequently dehydrated in graded ethanol followed by xylene and mounted with glass coverslips using DPX.

Statistical analysis. All statistical significance was set at $\mathrm{P}<0.05$. Statistical analyses were performed using the StatView software (version 5.0J, SAS Institute Inc., Cary, NC, USA).

\section{Results}

Effects of 5-FU and/or metformin on the growth of OSCC cells in vitro. The growth inhibitory effect of 5-FU and metformin on HSC2, HSC 3 and HSC4 cells was analyzed by the MTT assay. Cells were treated with 5-FU $(0.5-10 \mu \mathrm{g} / \mathrm{ml})$ and/or metformin $(1-10 \mathrm{mg} / \mathrm{ml})$ for 24,48 and $72 \mathrm{~h}$. 5-FU or metformin inhibited

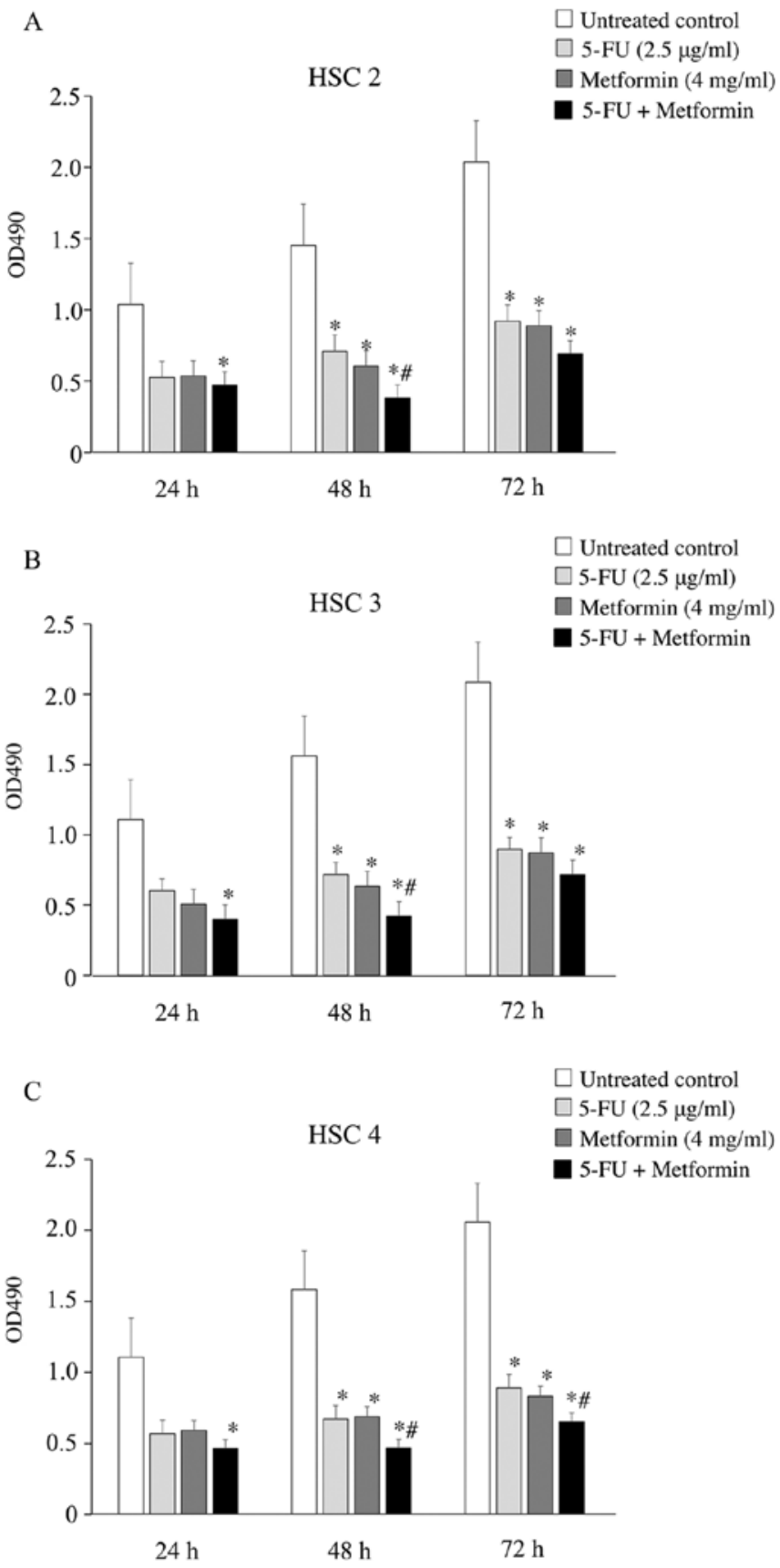

Figure 1. Effect of 5-FU and/or metformin treatment on OSCC cell proliferation in vitro. Inhibition of cell growth was evaluated by MTT assay. (A) 5-FU and metformin combined treatment significantly inhibited the growth of HSC2 cells compared to 5-FU or metformin alone, or the untreated control after $48 \mathrm{~h}$ of treatment. (B) In case of HSC 3 cells, similar result was observed as HSC2. (C) 5-FU and metformin combined treatment significantly inhibited the growth of HSC4 cells compared to either agent alone, or the untreated control after 48 and $72 \mathrm{~h}$ of treatment. Error bars represent the standard deviation of the mean of six independent experiments. ${ }^{*} \mathrm{P}<0.01$ when compared to that of control (Mann-Whitney U test). ${ }^{\text {" }} \mathrm{P}<0.01$ when compared to that of each agent alone (Mann-Whitney U test).

cell growth in a dose-dependent manner, and single treatment with $2.5 \mu \mathrm{g} / \mathrm{ml} 5$-FU or $4 \mathrm{mg} / \mathrm{ml}$ metformin inhibited $\geq 50 \%$ cell growth in all three cell lines (data not shown). Therefore, these concentrations of 5-FU and metformin were chosen for all in vitro experiments as single or combination treatments. As shown in Fig. 1,5-FU and metformin combination significantly inhibited the growth of $\mathrm{HSC} 2, \mathrm{HSC} 3$ and $\mathrm{HSC} 4$ cells compared 


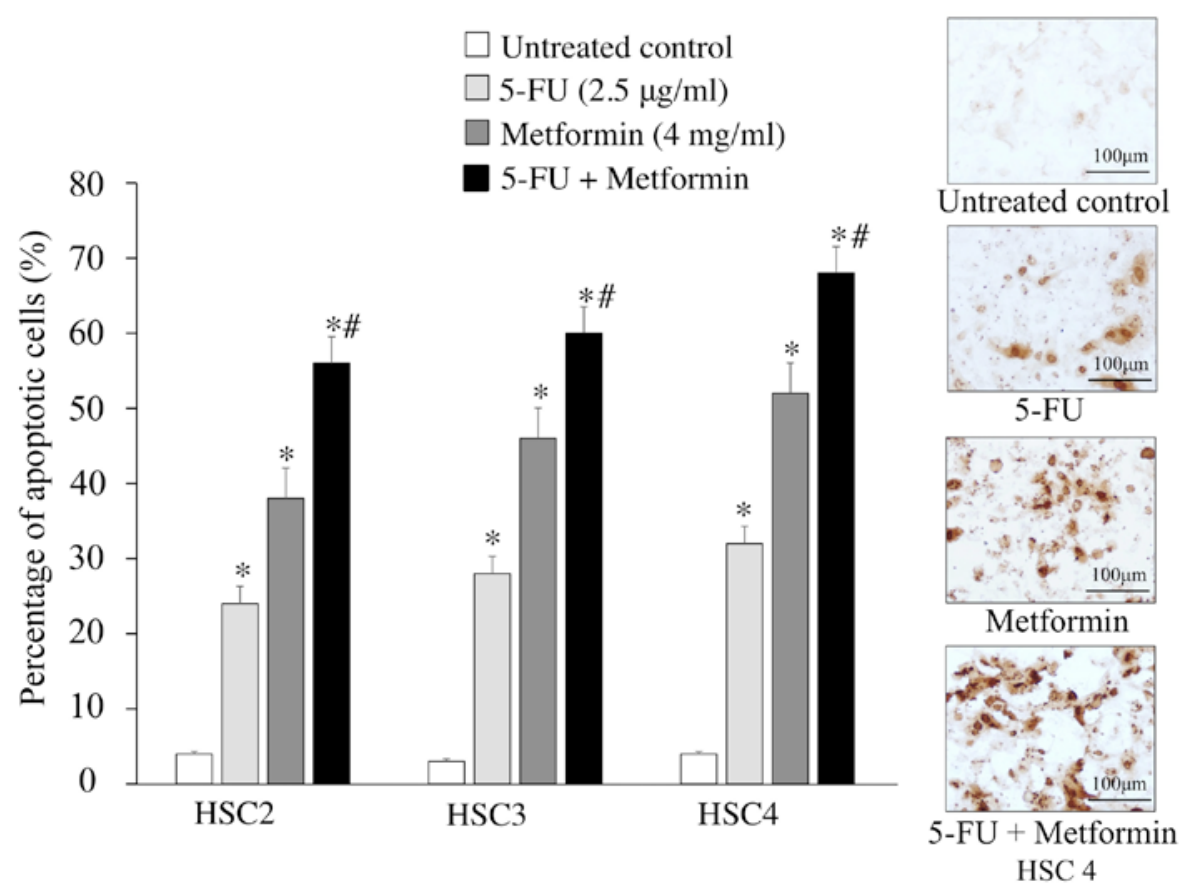

Figure 2. Effect of 5-FU and/or metformin treatment on OSCC cell apoptosis in vitro. TUNEL assay was performed to confirm the apoptotic inducing activity of 5-FU and/or metformin treatment. The numbers of apoptotic cells were significantly increased after 5-FU and metformin combined treatment than treatment with either agent alone. Error bars represent the standard deviation of the mean of TUNEL positive cells in three random fields of each cover glass. TUNEL positive cells (brown color) in HSC4 cells are shown on the right. ${ }^{*} \mathrm{P}<0.01$ when compared to that of control (Mann-Whitney $\mathrm{U}$ test). ${ }^{\text {"P }}<0.01$ when compared to that of each agent alone (Mann-Whitney U test).

to 5-FU or metformin alone, or the untreated control. In addition, $48 \mathrm{~h}$ treatment was the most effective (growth inhibition ratio: $70-73 \%$ ) for all three cell lines.

Effects of 5-FU and/or metformin on induction of apoptosis in vitro. To understand whether the enhanced cell growth inhibitory effect of 5-FU and metformin combined treatment was due to apoptosis, we performed TUNEL assay to detect DNA fragmentation and chromatin condensation in treated cells. TUNEL assay showed that 5-FU $(2.5 \mu \mathrm{g} / \mathrm{ml})$ and metformin ( $4 \mathrm{mg} / \mathrm{ml}$ ) combination treatment for $48 \mathrm{~h}$ induced apoptosis (56-68\%) more strongly in cells compared to single agent chemotherapy. Briefly, the numbers of apoptotic cells were significantly increased after 5-FU and metformin combined treatment than treatment with either agent alone (Fig. 2).

Effects of 5-FU and/or metformin on the production of lactate in vitro. To clarify the mechanisms of the antitumor activity of 5-FU and metformin combined treatment, we examined the production of lactate in cells that was relevant to the Warburg effect. Lactate colorimetric assay detected a decreased level $(\leq 1.7 \mathrm{ng} / \mathrm{mol})$ of lactate in the supernatants of 5-FU $(2.5 \mu \mathrm{g} / \mathrm{ml})$ and metformin $(4 \mathrm{mg} / \mathrm{ml})$ treated cells compared to untreated control cells $(\leq 7 \mathrm{ng} / \mathrm{mol})$, or cells treated with $5-\mathrm{FU}(\leq 5.7 \mathrm{ng} / \mathrm{mol})$ or metformin $(\leq 3.9 \mathrm{ng} / \mathrm{mol})$ alone. Briefly, metformin reduced the production of lactate in the three cell groups compared to 5-FU, whereas 5-FU and metformin combined treatment markedly reduced the production of lactate in the three cell groups compared to either agent alone (Fig. 3).

Effects of 5-FU and/or metformin on the expression levels of Warburg effect related factors in vitro. In order to clarify

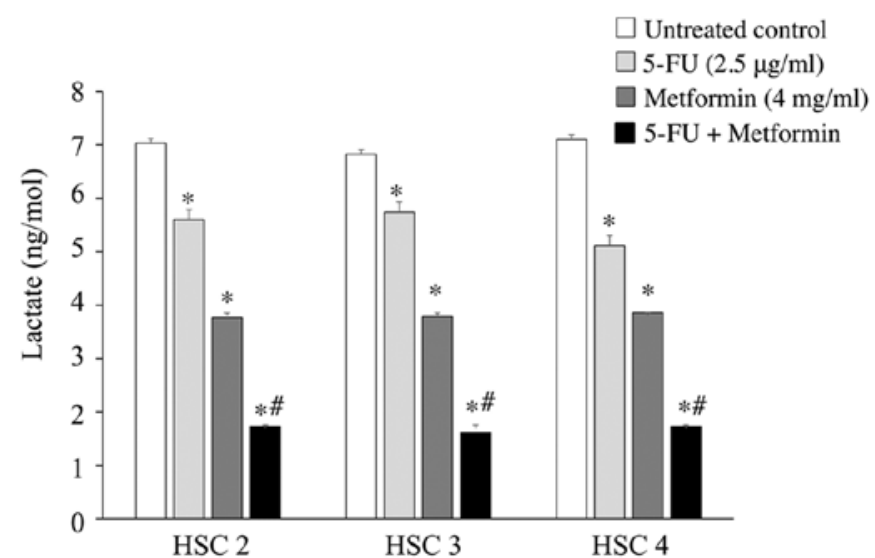

Figure 3. Effect of 5-FU and/or metformin treatment on lactate production in vitro. Lactate colorimetric assay detected a decreased level of lactate in the supernatants of 5-FU and metformin treated cells compared to untreated control cells, or cells treated with $5-\mathrm{FU}$ or metformin alone. ${ }^{*} \mathrm{P}<0.01$ when compared to that of control (Mann-Whitney U test). ${ }^{\text {"P }}<0.01$ when compared to that of each agent alone (Mann-Whitney U test).

whether or not 5-FU and/or metformin treatment modulates the Warburg effect related factors in tumor cells, we examined the expression levels of HIF-1- $\alpha$, mTOR, Akt1 and AMPK $\alpha$ in 5-FU and/or metformin treated ( $48 \mathrm{~h}$ ) cells by western blotting. Metformin markedly reduced the expression of HIF-1- $\alpha$ and mTOR, and slightly reduced the expression of Akt1 in all three cell lines and induced the expression of AMPK $\alpha$ in HSC3 and HSC4. In addition, 5-FU and metformin combined treatment reduced the expression of HIF-1- $\alpha$, mTOR and Akt1, and induced the expression of AMPK $\alpha$ markedly in all three cell lines (Fig. 4). 


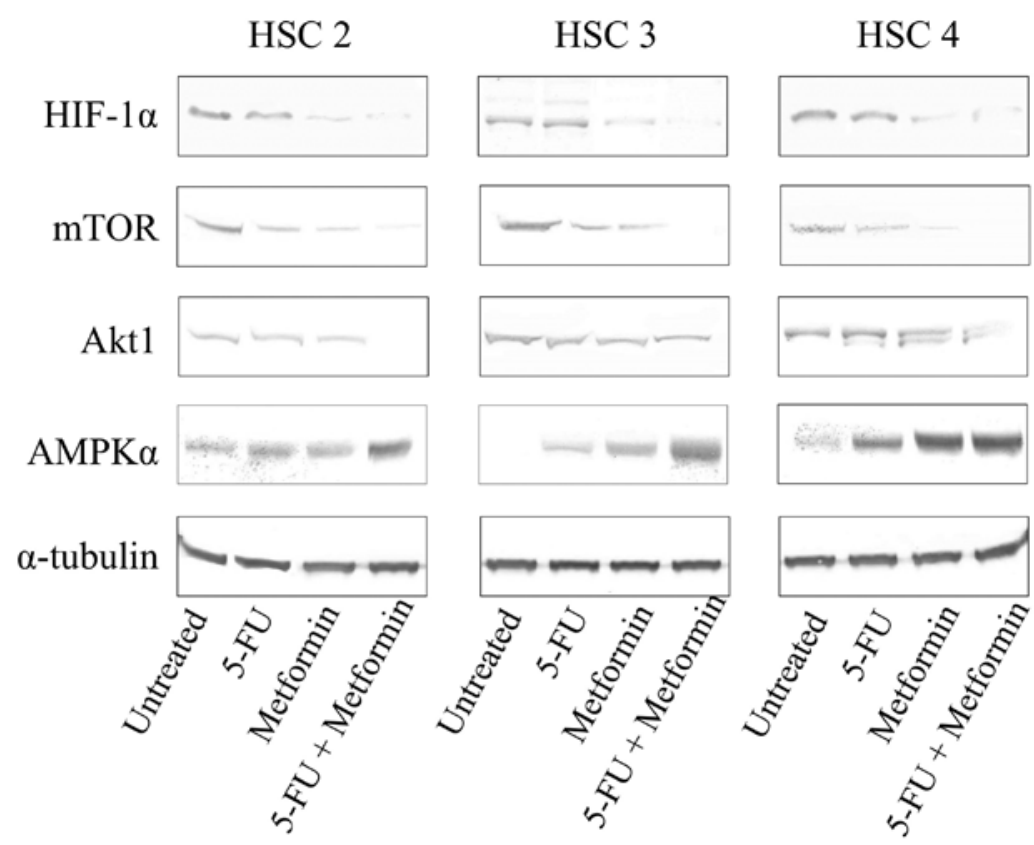

Figure 4. Expression of HIF-1 $\alpha$, mTOR, Akt1 and AMPK $\alpha$ protein in 5-FU and/or metformin treated OSCC cells. Western blot analysis demonstrated marked downregulation of HIF-1 $\alpha$, mTOR and Akt1 expression, and upregulation of AMPK $\alpha$ in cells treated with 5-FU and metformin combination treatment.

Effects of 5-FU and/or metformin on tumor growth inhibition in vivo. Nude mice with HSC2 tumor xenografts were used to examine the antitumor activity of 5-FU and metformin single/ combination treatment. Control group received saline $200 \mu \mathrm{l}$ only, while treatment groups were treated with either 5-FU $(10 \mathrm{mg} / \mathrm{kg} / \mathrm{day}, 5$ times/week) or metformin $(200 \mathrm{mg} / \mathrm{kg} / \mathrm{day}$, 5 times/week) alone, or in combination for 4 weeks (Fig. 5A). Fig. 5B shows the result of the in vivo experiment. All the treatment groups significantly inhibited tumor growth compared to the untreated control. Antitumor effect of 5-FU alone $(52 \%)$ was in the same range to metformin alone (59.9\%). However, the maximum reduction $(77.6 \%)$ of tumor growth was observed with 5-FU and metformin combination therapy, which is significantly different than treatment with either agent alone. Compared to the control, mice in all treatment groups showed no toxicity or significant weight loss during the treatment (Fig. 5C).

Effects of 5-FU and/or metformin on the expression of Warburg effect related factors in vivo. We examined the expression levels of Warburg effect related factors (HIF-1- $\alpha$, mTOR, Akt1 and $\mathrm{AMPK} \alpha$ ) in mouse tumors by immunohistochemistry. The expression of HIF-1- $\alpha$ was detected in the nucleus of untreated $\mathrm{HSC} 2$ tumor cells and 5-FU treated $\mathrm{HSC} 2$ tumor cells. However, the expression of HIF-1- $\alpha$ was not detected in the nucleus of metformin treated tumor cells and 5-FU plus metformin treated tumor cells. Similar result was observed in case of mTOR, except mTOR expression was detected in the cytoplasm of tumor cells. The expression of Aktl was detected strongly in both the nucleus and the cytoplasm of untreated HSC2 tumor cells. However, the expression of Akt1 was detected weakly in 5-FU treated tumor cells, but it was not detected in metformin treated tumor cells or 5-FU plus metformin treated tumor cells. The expression of AMPK $\alpha$ was not detected in cytoplasm of untreated HSC2 tumor cells, but it was detected weakly in 5-FU treated tumor cells, moderately in metformin treated tumor cells, and strongly in 5-FU plus metformin treated tumor cells (Fig. 6).

Effects of 5-FU and/or metformin on induction of apoptosis in vivo. To detect the degree of apoptosis induced by 5-FU and/or metformin in vivo, the number of apoptotic cells in mouse tumor tissue sections was quantified by the TUNEL assay. Although treatment with 5-FU or metformin alone moderately induced apoptosis in mouse tumors compared to the untreated control, 5-FU and metformin combined treatment significantly upregulated the expression levels of TUNELpositive cells in mouse tumors than all other treatment groups or control (Fig. 7).

\section{Discussion}

The efficacy of 5-FU in combination with metformin on OSCC both in vitro and in vivo was shown. In addition, this study suggests that metformin may enhance the effect of 5-FU on OSCC through the inhibition of the Warburg effect.

Metformin is an oral hypoglycemic drug that has been used to treat type 2 diabetes mellitus, and belongs to the biguanide class. Because of its low cost compared to insulin, metformin is used worldwide. Epidemiologic studies and meta-analyses have suggested that type 2 diabetes mellitus patients have a higher incidence of malignancies in recent years (35-37). However, a Taiwanese study demonstrated that the increasing trends of oral cancer may not be ascribed to the increasing incidence of diabetes over the same period (5). The type 2 diabetes mellitus patients who received metformin have not only showed lowered cancer-associated mortality but also demonstrated decreased tumor incidence (38-41). Several studies indicated the preventive effects of metformin against thyroid, bladder, colon, prostate, breast, endometrial, 
A

Treatment schedule

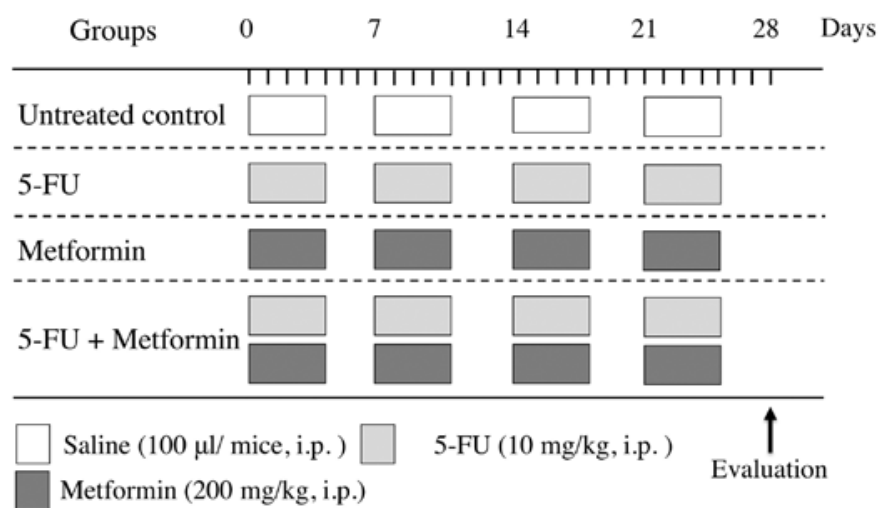

B

HSC 2 tumor
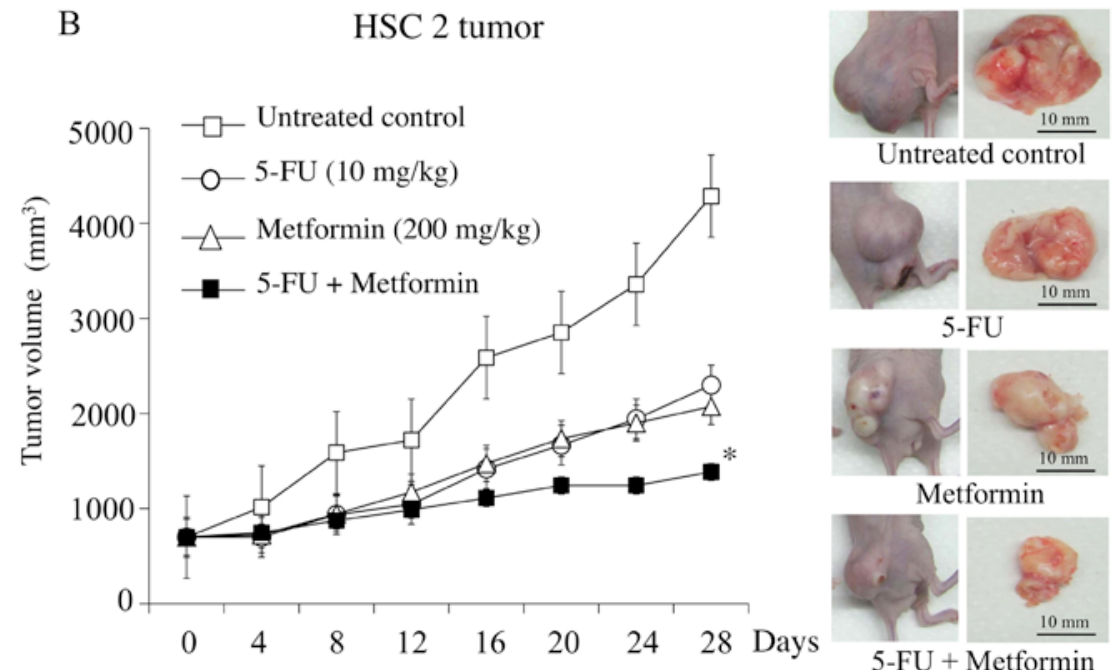

Metformin

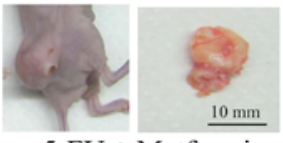

$5-\mathrm{FU}+$ Metformin

$\mathrm{C}$

HSC 2 tumor bearing mice

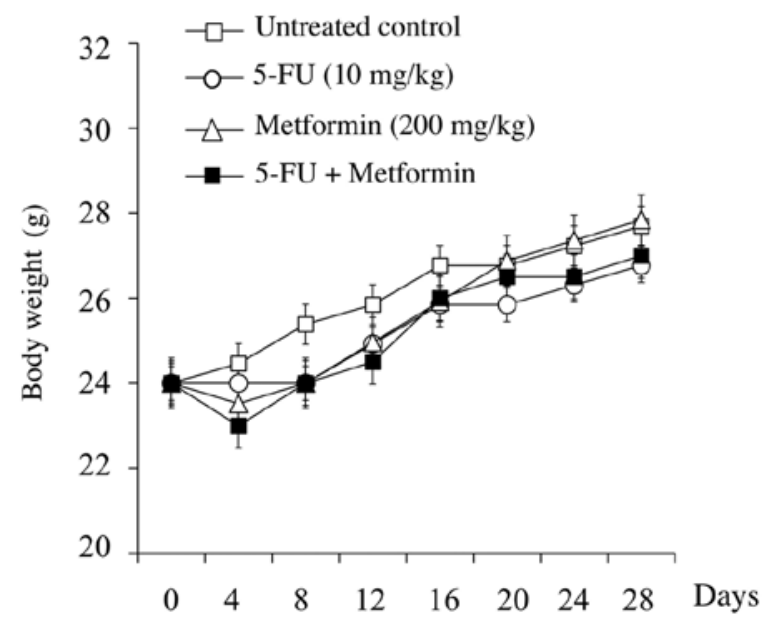

Figure 5. Effect of 5-FU and/or metformin treatment on HSC2 tumor growth and mouse body weight. (A) Treatment schedule. (B) Change of HSC2 tumor volume. (C) Change of mouse body weight. Cells $\left(1 \times 10^{6}\right)$ were inoculated into the backs of nude mice. When the tumors reached $600-800 \mathrm{~mm}^{3}$ in volume, they were treated with either $5-\mathrm{FU}$ (10 mg/kg, 5 times/week) or metformin $(200 \mathrm{mg} / \mathrm{kg}, 5$ times/week) alone, or in combination for 4 weeks. Tumor volume and body weight was measured every three days. 5-FU and metformin combination treatment most effectively reduced tumor growth compared to 5-FU or metformin single treatment, or untreated control (saline alone). Mice in all treatment groups showed no significant weight loss during the treatment when compared to control mice. Error bars represent the standard error of the mean results from five mice $(n=5)$. " $P<0.01$ when compared to that of each agent alone or control (one-way ANOVA).

ovarian and oral cancer in patients with type 2 diabetes mellitus (20-27). Therefore, effectiveness of metformin against oral cancer should be evaluated. Available in vitro and in vivo studies demonstrated that, metformin could exert 
A $\mathrm{HIF}-1 \alpha$
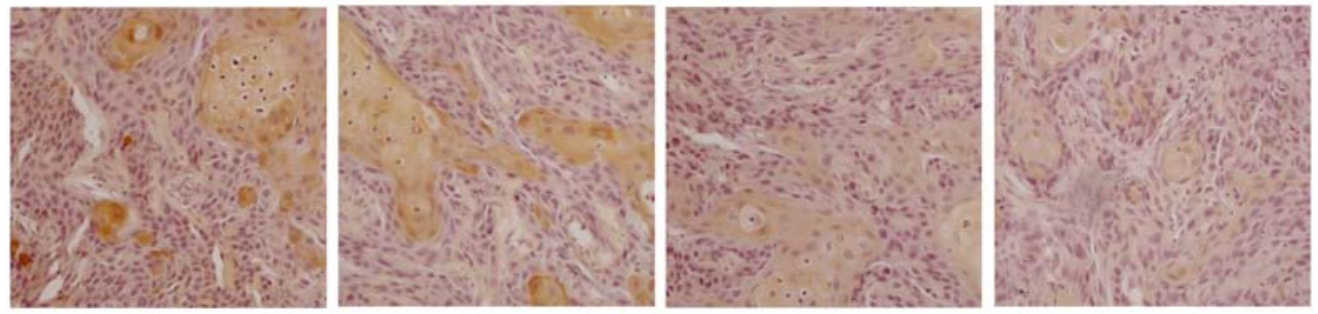

mTOR

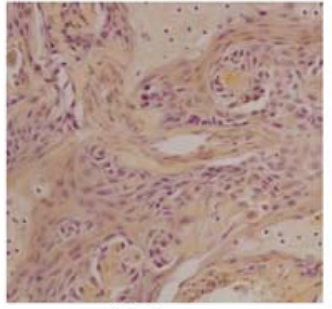

Saline

B Akt1

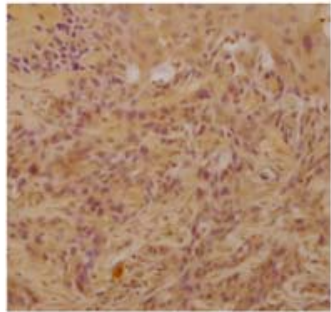

\section{$\operatorname{AMPK} \alpha$}

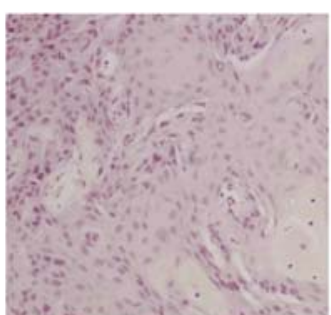

Saline

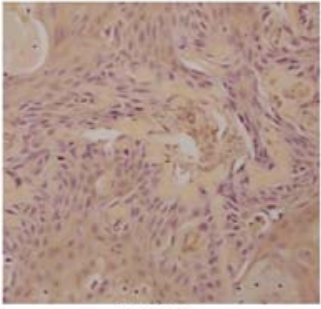

$5-\mathrm{FU}$

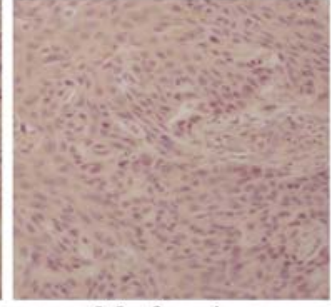

Metformin

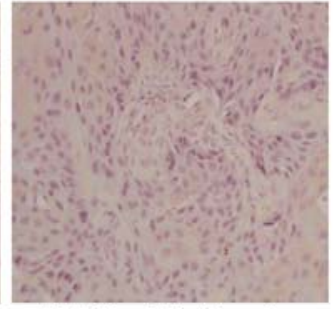

$5-\mathrm{FU}+$ Metformin
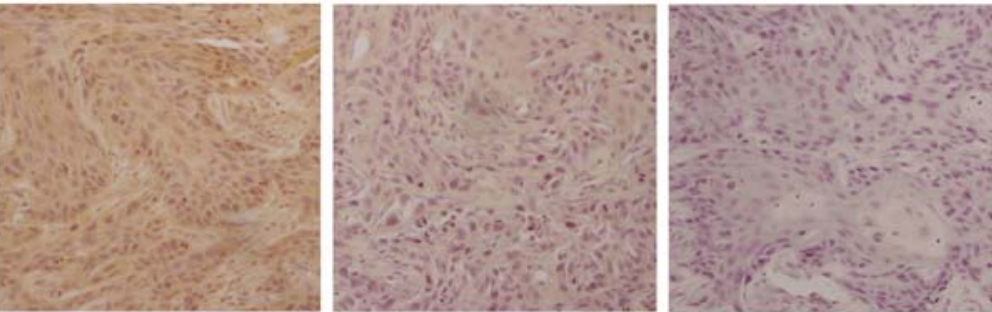

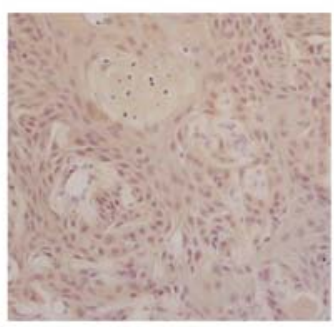

5 -FU

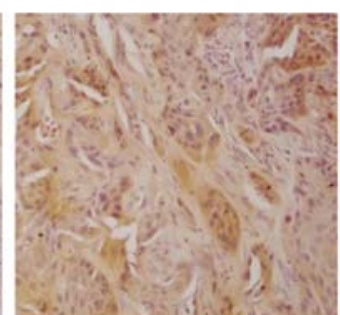

Metformin

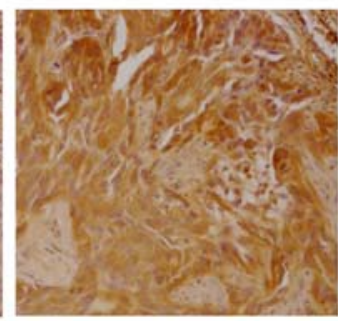

$5-\mathrm{FU}+$ Metformin

Figure 6. Effects of 5-FU and/or metformin on the expression of Warburg effect related factors in vivo. Immunohistchemical staining was performed to investigate the expression of Warburg effect related factors (HIF-1- $\alpha$, mTOR, Akt1 and AMPK $\alpha$ ) in mouse tumors by immunohistochemistry. (A) HIF-1- $\alpha$ and mTOR. (B) Akt1 and AMPK $\alpha$. Downregulation of HIF-1 $\alpha$, mTOR and Akt1 expression, and upregulation of AMPK $\alpha$ was seen in HSC2 tumor treated with 5-FU and metformin combination.

growth inhibitory effects on various human cancer cell types, such as head and neck, pancreas, prostate, breast, stomach and liver $(12,42-46)$. It was reported that carcinogenesis can be directly promoted by insulin resistance and resultant hyperinsulinemia in diabetic patients and metformin could reduce risk of cancer by maintaining insulin resistance, blood glucose and insulin levels $(47,48)$. However, other antidiabetic drug, e.g. pioglitazone improves insulin resistance in diabetic patients but has a neutral effect against oral cancer. Therefore, metformin might have other additional mechanisms of actions against cancer and unlike other antidiabetic drug it might be useful in the treatment of cancer (49).

The anticancer effects of metformin are its direct pleiotropic inhibitory effects on several pathways involved in survival and metastasis of cancer cells (48). At the cellular level, main mechanisms of metformin against cancer cells are activation of AMPK, mediating the PI3K/Akt signaling pathway, inducing G1-phase arrest with induction of cyclindependent kinase inhibitor 1B (p27) and inhibition of mTOR and HIF-1 $\alpha(19,50,51)$. Metformin can reduce the antisenescence effects of EMT program in cancer cells and can inhibit proliferation of CSCs (28). Furthermore, metformin can potentiate the effect of chemotherapeutic agents or reverse drug resistance in cancer cells $(13,38,52)$. Therefore, we examined the possibility of metformin combination therapy with chemotherapeutic agents available for OSCC in Japan preexperimentally. In the preliminary experiment, we observed that the growth inhibitory effect of 5-FU in combination with metformin against OSCC cells was significantly higher when compared to cisplatin, docetaxel or paclitaxel. However, the 


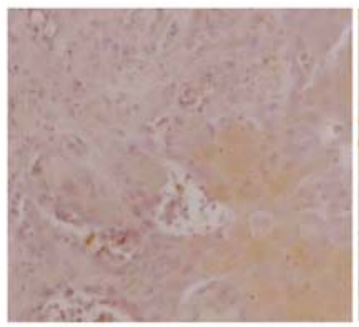

Saline

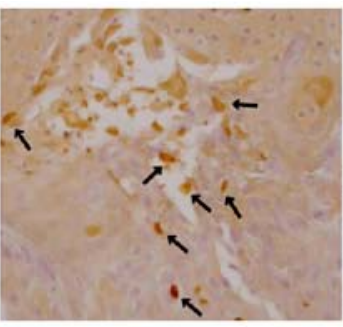

5-FU

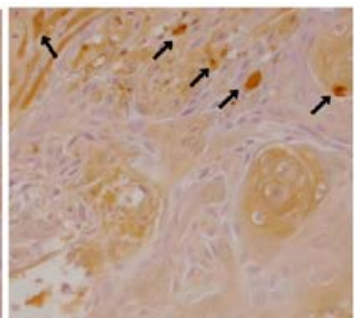

Metformin

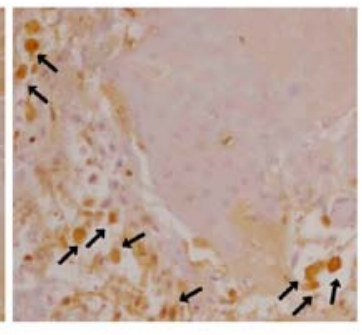

5 -FU + Metformin

$\uparrow$ TUNEL positive cells

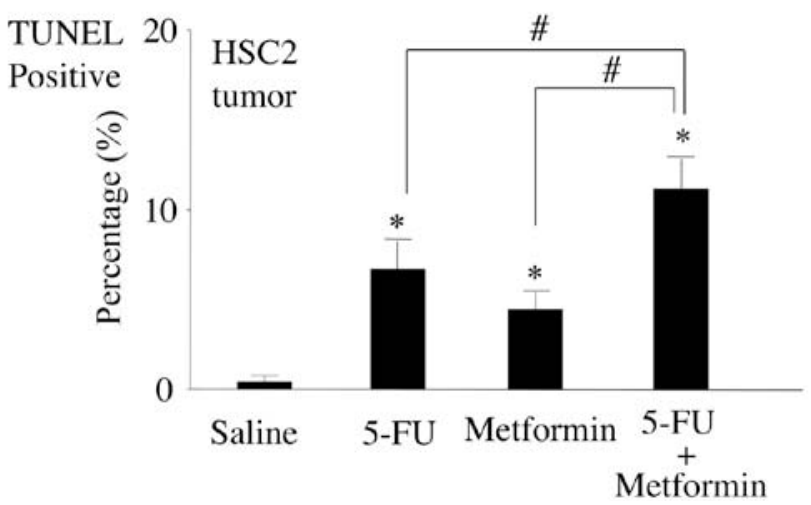

Figure 7. Effects of 5-FU and/or metformin on induction of apoptosis in vivo. A TUNEL assay was performed to quantify the number of apoptotic cells in treated HSC2 tumors. Cells stained brown after TUNEL staining, which indicates that apoptosis occurred in tumors treated with 5-FU and/or metformin. The TUNEL assay showed significantly increased number of apoptotic cells in 5-FU and metformin combined treatment tumors. Error bars represent the standard error of the mean results from five mice $(n=5)$. $\mathrm{P}<0.01$ when compared to that of Control (Mann-Whitney $\mathrm{U}$ test). ${ }^{*} \mathrm{P}<0.01$ when compared to that of each agent alone (Mann-Whitney U test).

mechanism of the growth inhibitory effect of 5-FU in combination with metformin is still unclear.

In this study, we focused our attention on inhibition of the Warburg effect by $5-\mathrm{FU}$ in combination with metformin. In accordance with our expectation, metformin alone exerted marked inhibitory effect on Warburg effect in OSCC cells, and in combination with 5-FU it showed more prominent inhibitory effect on Warburg effect. Briefly, 5-FU in combination with metformin significantly suppressed the production of lactate (Fig. 3), and it could reduce the expression of HIF-1- $\alpha$, mTOR and Akt1 and induce the expression of AMPK $\alpha$ than either agent alone (Figs. 4 and 6). Moreover, the level of inhibition of Warburg effect by 5-FU in combination with metformin seemed to be relative to the growth inhibitory effect (Fig. 1), apoptosis inducing effect (Figs. 2 and 7), and antitumor effect (Fig. 5B). Furthermore, it has been reported that metformin is well tolerated by patients, it is absorbed into the body within 1-3 h after oral administration and $90 \%$ of it is eliminated by the renal system (28). The combined treatment with 5-FU and metformin may be an attractive option compared to other cytotoxic therapeutic agents because in our study, mice treated with 5-FU in combination with metformin showed no toxicity or significant weight loss during the treatment when compared to the untreated control mice (Fig. 5C).

As an OSCC treatment strategy, recently we tend to select the heavy use of costly molecularly targeted drugs for OSCC treatment. Instead, a more desirable strategy could be selecting low cost, effective and less cytotoxic drugs against OSCC. In this experiment, we showed that FU and metformin combina- tion therapy effectively suppressed the growth of OSCC cells/ tumors and could modulate the regulator molecules of the Warburg effect in cancer cells more than our expectations. These findings suggest that 5-FU and metformin combination treatment might be regarded as a potential treatment strategy for human OSCC. Future studies should aim at defining the most appropriate dose and schedule of administration of this combination treatment.

\section{Acknowledgements}

This study was supported in part by a Grant-in-Aid from the Japanese Ministry of Education, Science and Culture.

\section{References}

1. Yakob M, Fuentes L, Wang MB, Abemayor E and Wong DT: Salivary biomarkers for detection of oral squamous cell carcinoma - current state and recent advances. Curr Oral Health Rep 1: 133-141, 2014.

2. Exarchos KP, Goletsis Y and Fotiadis DI: A multiscale and multiparametric approach for modeling the progression of oral cancer. BMC Med Inform Decis Mak 12: 136, 2012.

3. Parkin DM, Bray F, Ferlay J and Pisani P: Global cancer statistics, 2002. CA Cancer J Clin 55: 74-108, 2005.

4. Ferlay J, Shin HR, Bray F, Forman D, Mathers C and Parkin DM: Estimates of worldwide burden of cancer in 2008: GLOBOCAN 2008. Int J Cancer 127: 2893-2917, 2010.

5. Tseng CH: Oral cancer in Taiwan: Is diabetes a risk factor? Clin Oral Investig 17: 1357-1364, 2013.

6. The Oral Cancer Foundation: Oral Cancer Facts. Website: http:// www.oralcancerfoundation.org/facts/. Access date: February 28, 2016.

7. Rivera C: Essentials of oral cancer. Int J Clin Exp Pathol 8: 11884-11894, 2015. 
8. Zini A, Czerninski R and Sgan-Cohen HD: Oral cancer over four decades: Epidemiology, trends, histology, and survival by anatomical sites. J Oral Pathol Med 39: 299-305, 2010.

9. Inagi K, Takahashi H, Okamoto M, Nakayama M, Makoshi T and Nagai H: Treatment effects in patients with squamous cell carcinoma of the oral cavity. Acta Otolaryngol (Suppl) 547: 25-29, 2002

10. Shingaki S, Takada M, Sasai K, Bibi R, Kobayashi T, Nomura T and Saito C: Impact of lymph node metastasis on the pattern of failure and survival in oral carcinomas. Am J Surg 185: 278-284, 2003.

11. Ogawa T, Washio J, Takahashi T, Echigo S and Takahashi N: Glucose and glutamine metabolism in oral squamous cell carcinoma: Insight from a quantitative metabolomic approach Oral Surg Oral Med Oral Pathol Oral Radiol 118: 218-225, 2014

12. Warburg O: On the origin of cancer cells. Science 123: 309-314, 1956.

13. Xu RH, Pelicano H, Zhou Y, Carew JS, Feng L, Bhalla KN, Keating MJ and Huang P: Inhibition of glycolysis in cancer cells: A novel strategy to overcome drug resistance associated with mitochondrial respiratory defect and hypoxia. Cancer Res 65 613-621, 2005.

14. Feron O: Pyruvate into lactate and back: From the Warburg effect to symbiotic energy fuel exchange in cancer cells. Radiother Oncol 92: 329-333, 2009.

15. Courtnay R, Ngo DC, Malik N, Ververis K, Tortorella SM and Karagiannis TC: Cancer metabolism and the Warburg effect: The role of HIF-1 and PI3K. Mol Biol Rep 42: 841-851, 2015.

16. Shaw RJ and Cantley LC: Ras, PI(3)K and mTOR signalling controls tumour cell growth. Nature 441: 424-430, 2006.

17. Faubert B, Boily G, Izreig S, Griss T, Samborska B, Dong Z, Dupuy F, Chambers C, Fuerth BJ, Viollet B, et al: AMPK is a negative regulator of the Warburg effect and suppresses tumor growth in vivo. Cell Metab 17: 113-124, 2013.

18. Quinn BJ, Kitagawa H, Memmott RM, Gills JJ and Dennis PA: Repositioning metformin for cancer prevention and treatment. Trends Endocrinol Metab 24: 469-480, 2013.

19. Rêgo DF, Pavan LM, Elias ST, De Luca Canto G and Guerra EN: Effects of metformin on head and neck cancer: A systematic review. Oral Oncol 51: 416-422, 2015.

20. Tseng CH: Metformin reduces thyroid cancer risk in Taiwanese patients with type 2 diabetes. PLoS One 9: e109852, 2014.

21. Tseng CH: Metformin may reduce bladder cancer risk in Taiwanese patients with type 2 diabetes. Acta Diabetol 51: 295-303, 2014.

22. Tseng CH: Diabetes, metformin use, and colon cancer: A population-based cohort study in Taiwan. Eur J Endocrinol 167: 409-416, 2012

23. Tseng $\mathrm{CH}$ : Metformin significantly reduces incident prostate cancer risk in Taiwanese men with type 2 diabetes mellitus. Eur J Cancer 50: 2831-2837, 2014.

24. Tseng $\mathrm{CH}$ : Metformin may reduce breast cancer risk in Taiwanese women with type 2 diabetes. Breast Cancer Res Treat 145: 785-790, 2014.

25. Tseng $\mathrm{CH}$ : Metformin and endometrial cancer risk in Chinese women with type 2 diabetes mellitus in Taiwan. Gynecol Oncol 138: 147-153, 2015.

26. Tseng $\mathrm{CH}$ : Metformin reduces ovarian cancer risk in Taiwanese women with type 2 diabetes mellitus. Diabetes Metab Res Rev 31: 619-626, 2015.

27. Tseng $\mathrm{CH}$ : Metformin may reduce oral cancer risk in patients with type 2 diabetes. Oncotarget 7: 2000-2008, 2016.

28. Del Barco S, Vazquez-Martin A, Cufí S, Oliveras-Ferraros C, Bosch-Barrera J, Joven J, Martin-Castillo B and Menendez JA: Metformin: Multi-faceted protection against cancer. Oncotarget 2: 896-917, 2011

29. Chen G, Xu S, Renko K and Derwahl M: Metformin inhibits growth of thyroid carcinoma cells, suppresses self-renewal of derived cancer stem cells, and potentiates the effect of chemotherapeutic agents. J Clin Endocrinol Metab 97: E510-E520, 2012.

30. Ling S, Feng T, Ke Q, Fan N, Li L, Li Z, Dong C, Wang C, $\mathrm{Xu} \mathrm{F}, \mathrm{Li} \mathrm{Y}$, et al: Metformin inhibits proliferation and enhances chemosensitivity of intrahepatic cholangiocarcinoma cell lines. Oncol Rep 31: 2611-2618, 2014.

31. Honjo S, Ajani JA, Scott AW, Chen Q, Skinner HD, Stroehlein J, Johnson RL and Song S: Metformin sensitizes chemotherapy by targeting cancer stem cells and the mTOR pathway in esophageal cancer. Int J Oncol 45: 567-574, 2014.
32. Wu X, He C, Wu Y and Chen X: Synergistic therapeutic effects of Schiff's base cross-linked injectable hydrogels for local co-delivery of metformin and 5-fluorouracil in a mouse colon carcinoma model. Biomaterials 75: 148-162, 2016.

33. Zhao Q, Wang J, Zou MJ, Hu R, Zhao L, Qiang L, Rong JJ, You QD and Guo QL: Wogonin potentiates the antitumor effects of low dose 5-fluorouracil against gastric cancer through induction of apoptosis by down-regulation of NF-kappaB and regulation of its metabolism. Toxicol Lett 197: 201-210, 2010.

34. Rattan R, Graham RP, Maguire JL, Giri S and Shridhar V: Metformin suppresses ovarian cancer growth and metastasis with enhancement of cisplatin cytotoxicity in vivo. Neoplasia 13 483-491, 2011.

35. Nicolucci A: Epidemiological aspects of neoplasms in diabetes. Acta Diabetol 47: 87-95, 2010.

36. Decensi A, Puntoni M, Goodwin P, Cazzaniga M, Gennari A, Bonanni B and Gandini S: Metformin and cancer risk in diabetic patients: A systematic review and meta-analysis. Cancer Prev Res (Phila) 3: 1451-1461, 2010

37. Rizos CV and Elisaf MS: Metformin and cancer. Eur J Pharmacol 705: 96-108, 2013

38. Currie CJ, Poole CD, Jenkins-Jones S, Gale EA, Johnson JA and Morgan CL: Mortality after incident cancer in people with and without type 2 diabetes: Impact of metformin on survival. Diabetes Care 35: 299-304, 2012.

39. Landman GW, Kleefstra N, van Hateren KJ, Groenier KH, Gans RO and Bilo HJ: Metformin associated with lower cancer mortality in type 2 diabetes: ZODIAC-16. Diabetes Care 33: 322-326, 2010.

40. Ruiter R, Visser LE, van Herk-Sukel MP, Coebergh JW, Haak HR, Geelhoed-Duijvestijn PH, Straus SM, Herings RM and Stricker BH: Lower risk of cancer in patients on metformin in comparison with those on sulfonylurea derivatives: Results from a large population-based follow-up study. Diabetes Care 35: 119-124, 2012.

41. Libby G, Donnelly LA, Donnan PT, Alessi DR, Morris AD and Evans JM: New users of metformin are at low risk of incident cancer: A cohort study among people with type 2 diabetes. Diabetes Care 32: 1620-1625, 2009.

42. Nair V, Pathi S, Jutooru I, Sreevalsan S, Basha R, Abdelrahim M, Samudio I and Safe S: Metformin inhibits pancreatic cancer cell and tumor growth and downregulates $\mathrm{Sp}$ transcription factors. Carcinogenesis 34: 2870-2879, 2013.

43. Akinyeke T, Matsumura S, Wang X, Wu Y, Schalfer ED, Saxena A, Yan W, Logan SK and Li X: Metformin targets c-MYC oncogene to prevent prostate cancer. Carcinogenesis 34: 2823-2832, 2013

44. Alimova IN, Liu B, Fan Z, Edgerton SM, Dillon T, Lind SE and Thor AD: Metformin inhibits breast cancer cell growth, colony formation and induces cell cycle arrest in vitro. Cell Cycle 8: 909-915, 2009.

45. Kato K, Gong J, Iwama H, Kitanaka A, Tani J, Miyoshi H, Nomura K, Mimura S, Kobayashi M, Aritomo Y, et al: The antidiabetic drug metformin inhibits gastric cancer cell proliferation in vitro and in vivo. Mol Cancer Ther 11: 549-560, 2012

46. Petrushev B, Tomuleasa C, Soritau O, Aldea M, Pop T, Susman S, Kacso G, Berindan I, Irimie A and Cristea V: Metformin plus PIAF combination chemotherapy for hepatocellular carcinoma. Exp Oncol 34: 17-24, 2012.

47. Viollet B, Guigas B, Sanz Garcia N, Leclerc J, Foretz M and Andreelli F: Cellular and molecular mechanisms of metformin: An overview. Clin Sci (Lond) 122: 253-270, 2012.

48. Martin-Castillo B, Vazquez-Martin A, Oliveras-Ferraros C and Menendez JA: Metformin and cancer: doses, mechanisms and the dandelion and hormetic phenomena. Cell Cycle 9: 1057-1064, 2010.

49. Tseng $\mathrm{CH}$ : Pioglitazone and oral cancer risk in patients with type 2 diabetes. Oral Oncol 50: 98-103, 2014.

50. Takiyama Y, Harumi T, Watanabe J, Fujita Y, Honjo J, Shimizu N, Makino $Y$ and Haneda M: Tubular injury in a rat model of type 2 diabetes is prevented by metformin: A possible role of HIF-1a expression and oxygen metabolism. Diabetes 60: 981-992, 2011.

51. Tanaka R, Tomosugi M, Horinaka M, Sowa $Y$ and Sakai T: Metformin causes G1-phase arrest via down-regulation of MiR-221 and enhances TRAIL sensitivity through DR5 up-regulation in pancreatic cancer cells. PLoS One 10: e0125779, 2015.

52. Ashinuma H, Takiguchi Y, Kitazono S, Kitazono-Saitoh M, Kitamura A, Chiba T, Tada Y, Kurosu K, Sakaida E, Sekine I, et al: Antiproliferative action of metformin in human lung cancer cell lines. Oncol Rep 28: 8-14, 2012. 